\title{
Railway suicides are less likely to occur on rainy days : Evidence from Japan
}

\author{
Hajime Sueki ${ }^{*}$
}

\begin{abstract}
Background: Patrols at stations and along railway lines can reduce the number of railway suicides; however, it is not sufficiently clear when railway suicides are most likely to occur. Aim: We examined the relationship between daily rainfall and the occurrence of railway suicides. Methods: We received the locations and daily data on the occurrence of railway suicides from a major railroad company in Japan. We also collected rainfall data from the Japan Meteorological Agency database for a roughly central locations of the railroad company. The study covered a period of five years, from April 2016 to March 2021. Results: Suicides occurred on 23 rainy days (3.9\%) and 92 nonrainy days (7.4\%). The incidence of suicides on rainy days was significantly lower than that on nonrainy days. Limitations: We were not able to obtain daily data on the number of rail passengers; therefore, could not rule out the possibility that the suicide incidence rate is lower on rainy days because the number of railroad users is lower on such days. Conclusion: Information about the weather could be used to improve the efficiency of patrols to prevent railway suicides.
\end{abstract}

Keywords:

Suicide prevention; suicide hotspots; railway suicide; transportation

1 Faculty of Human Sciences, Wako University, 5-1-1 Kanaigaoka, Machida, Tokyo, 195-8585, Japan

* Corresponding author: Hajime Sueki, Faculty of Human Sciences, Wako University, 5-1-1 Kanaigaoka, Machida, Tokyo, 195-8585, Japan, h_sueki@wako.ac.jp, Tel: +81-44-989-7777. 
Railway suicides on rainy days 2

While railroads are an important transportation infrastructure worldwide, they are often used as a means of suicide. Suicide is not only a grave tragedy for the individual, but it also has a profound impact on those left behind. In addition, railway suicide causes huge economic losses to society as a whole. The Ministry of Land, Infrastructure, Transport and Tourism in Japan (2010) estimated the economic loss of JPY 89 million (about USD 0.8 million) per railway suicide. In Japan, there are about 600 railway suicides every year (Ministry of Land, Infrastructure, Transport and Tourism in Japan, 2010), hence, the total loss is JPY 50 billion per year. This estimate is the monetary value of the time lost by passengers due to transportation delays and is a minimum value that does not account for the lives lost themselves, the damaged locomotive parts, the wages of the personnel cleaning up after the incident, or the psychological impact on the train drivers.

Many studies have reported that the installation of platform screen doors (Chung et al., 2016; Law et al., 2009; Mishara, 2007; Ueda et al., 2015) and anti-suicide pits (Coats \& Walter, 1999; O’Donnell \& Farmer, 1994) are effective in preventing suicides. However, the physical modification of stations and platforms is not always feasible, and the costs involved are high. A less costly method of preventing suicides along railway line is the installation of surveillance units (Niederkrotenthaler et al., 2012). However, it is impossible to keep a constant watch on every part of the railway line, and it is difficult for this measure to work effectively unless the conditions under which railway suicides are likely to occur are identified.

The conditions under which railway suicides occur are still unclear. Railway suicides are more likely to occur at stations with passing trains or fast trains (Niederkrotenthaler et al., 2012; Sueki, 2021). Railway suicides are also more likely to occur at stations with many passengers and a nearby psychiatric hospital (Sueki, 2021). However, as far as we know, other conditions are not known, and the predictability of the occurrence of railway suicides is low.

To improve the efficiency of patrols at stations and along railway lines for the purpose of preventing railway suicides, this study focused on weather. The weather is predictable to some extent in advance and could be used to make decisions on whether to conduct patrols. The impact of weather on suicide is complex (Deisenhammer, 2003), however, for railway suicides, which often occurred outdoors, it is expected that the incidence of railway suicides will be lower on rainy days because rainfall increases the cost of suicide attempt (e.g., getting wet on the way to the station). In this study, we tested the hypothesis that the incidence of railway suicides would be lower on rainy days than on non-rainy days.

\section{Methods}

\section{Data collection}

For the railway suicide data, we dealt with 116 incidences of death by suicide that occurred at major railway company stations and along railway lines in the Tokyo metropolitan area during a five-year period from April 2016 to March 2021 (1826 days). The railroad company 
Railway suicides on rainy days 3

provided us with data on the locations and dates of occurrences of the railway suicides. These data did not contain any personal information about persons who died by suicide. The railroad chosen for this study was a ground line and not a subway. Most stations did not have platform screen doors. At the request of the railroad company, its name has been anonymized. The determination of death by suicide was made by the Japanese police.

Rainfall data were obtained from the Japan Meteorological Agency (2021). We determined whether a day was a rainy day (rainfall $>0 \mathrm{~mm} /$ day) or a non-rainy day (rainfall $=0 \mathrm{~mm} /$ day) based on the five-year daily rainfall report at a point roughly in the center of the rail line of the railroad company that provided the data. The Tokyo metropolitan area is classified to have a humid subtropical climate, and snowfall is rarely observed throughout the year around the railroad used in this study.

\section{Statistical analysis}

A chi-square test was conducted to determine the association between the occurrence of railway suicides and weather conditions (rainy/non-rainy days). The p-values presented were for two-tailed tests. Analyses were performed using SPSS software (SPSS 24.0, SPSS Inc., Chicago, IL, USA).

\section{Results}

During the period under analysis, 116 incidences of railway suicides were identified. Suicides occurred on 115 days (6.3\%). There were 561 rainy days (30.7\%). Moreover, suicides occurred on 23 rainy days (3.9\%) and 92 non-rainy days (7.4\%). The incidence of suicides on rainy days (adjusted residual $=-2.8$ ) was significantly lower than that on non-rainy days $\left(\chi^{2}(1)=8.10, p=\right.$ $0.004)$.

\section{Discussion}

The results of this study showed that the incidence of railway suicides on rainy days (3.9\%) was approximately 0.52 times lower than that on non-rainy days (7.4\%), which means that the hypothesis is supported. If the resources available for suicide prevention are limited, it would be more effective to conduct patrols of hot spots along train lines and stations on sunny or cloudy days rather than rainy days.

The results of the present study provide some insight into the psychological state of those who choose railway suicides as a means of suicide, in that, the people attempting death by suicide are ambivalent about life and death (Shneidman, 1993). If they had made up their minds to attempt suicide, the trivial cost added by the rainy weather would not substantially reduce the incidence of suicide. Qualitative interviews with individuals who contemplated or attempted railway suicide indicated that planning for railway suicides may not be predetermined (Marsh et al., 2021). Fieldwork on suicide occurrence points in railroad stations showed that suicide attempts are more likely to occur near benches and waiting rooms (Sueki, 2021). All of these previous studies, along 
Railway suicides on rainy days 4

with the current one, have indicated that railway suicides are not always executed according to a predetermined plan with a strong intention to attempt suicide.

This is the first study to examine the relationship between weather conditions and the occurrence of railway suicide, rather than suicide as a whole. By limiting the means of suicide, we were able to identify a clear link between weather conditions and the occurrence of suicide.

However, this study has some limitations. First, we were not able to obtain daily data on the number of rail passengers. Therefore, we could not rule out the possibility that the suicide incidence rate is lower on rainy days because of the reduced number of railroad users on such days. A study on weather and transportation use in Japan (Noguchi, 1999) suggested that the number of commuters using public transportation increased during rainy days, while the number of passengers using public transportation for leisure, travel, and other purposes decreased, however, this does not necessarily mean that the number of railroad users decreased on rainy days. Second, all of the data were provided by one railway company in Japan, limiting the generalizability of the results.

Despite the above limitations, we were able to clarify one of the situations in which railway suicides tended to occur, that is, the railway suicide incidence is higher on the non-rainy days than on rainy days. Future research to clarify the situations in which railway suicides tend to occur will contribute to the prevention of suicide by improving the efficiency of patrols. 
Railway suicides on rainy days 5

\section{References}

Coats, T. J., \& Walter, D. P. (1999). Effect of station design on death in the London Underground: Observational study. BMJ, 319, 957-957. https://doi.org/10.1136/bmj.319.7215.957

Chung, Y. W., Kang, S. J., Matsubayashi, T., Sawada, Y., \& Ueda, M. (2016). The effectiveness of platform screen doors for the prevention of subway suicides in South Korea. Journal of Affective Disorders, 194, 80-83. https://doi.org/10.1016/j.jad.2016.01.026

Deisenhammer, E. A. (2003). Weather and suicide: The present state of knowledge on the association of meteorological factors with suicidal behaviour. Acta Psychiatrica Scandinavica, 108, 402409. https://doi.org/10.1046/j.0001-690X.2003.00209.x

Japan Meteorological Agency (2021). Historical weather data search. Retrieved from https:/www.data.jma.go.jp/obd/stats/etrn/index.php (accessed 13.8.2021)

Law, C. K., Yip, P. S., Chan, W. S., Fu, K. W., Wong, P. W., \& Law, Y. W. (2009). Evaluating the effectiveness of barrier installation for preventing railway suicides in Hong Kong. Journal of Affective Disorders, 114, 254-262. https://doi.org/10.1016/j.jad.2008.07.021

Marsh, I., Marzano, L., Mosse, D., \& Mackenzie, J. M. (2021). First-person accounts of the processes and planning involved in a suicide attempt on the railway. BJPsych Open, 7, e39. https://doi.org/10.1192/bjo.2020.173

Ministry of Land, Infrastructure, Transport and Tourism in Japan (2010). Investigation report on safety improvement by promoting understanding of railway users. Retrieved from http://www.mlit.go.jp/common/000120234.pdf (accessed 13.8.2021)

Mishara, B. L. (2007). Railway and metro suicides. Crisis, 28 Supplement 1, 36-43. https://doi.org/10.1027/0227-5910.28.S1.36

Niederkrotenthaler, T., Sonneck, G., Dervic, K., Nader, I. W., Voracek, M., Kapusta, N. D., Etzersdorfer, E., Mittendorfer-Rutz, E., \& Dorner, T. (2012). Predictors of suicide and suicide attempt in subway stations: A population-based ecological study. Journal of Urban Health: Bulletin of the New York Academy of Medicine, 89, 339-353. https://doi.org/10.1007/s11524011-9656-4

Noguchi, K. (1999). Modal choice of access trip to the railway station and users' evaluation: Comparison under the weather condition. City Planning Review. Special Issue, Papers on City Planning, 34, 979-984

O’Donnell, I., \& Farmer, R. D. (1994). The epidemiology of suicide on the London Underground. Social Science \& Medicine, 38, 409-418. https://doi.org/10.1016/0277-9536(94)90440-5

Shneidman, E. S. (1993). Suicide as psychache: A clinical approach to self-destructive behavior. Jason Aronson 
Railway suicides on rainy days 6

Sueki, H. (2021). Characteristics of train stations where railway suicides have occurred and locations within the stations. Crisis, 1-6. https://doi.org/10.1027/0227-5910/a000761

Ueda, M., Sawada, Y., \& Matsubayashi, T. (2015). The effectiveness of installing physical barriers for preventing railway suicides and accidents: Evidence from Japan. Journal of Affective Disorders, 178, 1-4. https://doi.org/10.1016/j.jad.2015.02.017 